This is the accepted version of the paper to be published as Janta, H., Lugosi, P. \& Brown, L., Coping with loneliness: A netnographic study of doctoral students, Journal of Further and Higher Education, DOI:10.1080/0309877X.2012.726972. Please consult the final published version if citing.

\title{
Coping with loneliness: A netnographic study of doctoral students
}

Dr Hania Janta, School of Hospitality and Tourism, University of Surrey

Dr Peter Lugosi*, Oxford School of Hospitality Management, Faculty of Business, Oxford Brookes University, Gipsy Lane, Oxford OX3 0BP, UK.

Email:plugosi@oxford.brookes.ac.uk

Dr Lorraine Brown, School of Tourism, Bournemouth University

*Corresponding author 


\begin{abstract}
This study aims to fill an empirical void in our understanding of how doctoral students, both domestic and international, cope with loneliness and isolation, and what types of tactics they use during different phases of their doctoral studies to overcome such issues. Data gathered through a netnographic study show that loneliness is a major problem for both domestic and international students and that it occurs at different stages of the doctoral study. Tactics used by participants to deal with this issue include multiple forms of (face to face and online) social interaction, professional development and escape from the doctorate. The paper discusses avenues for further research alongside some practical recommendations that might be implemented at universities to decrease feelings of isolation among students and further reduce drop-out rates.
\end{abstract}

Keywords: doctoral students, loneliness, netnography, coping, isolation 


\section{Introduction}

The doctoral experience can be described as an emotional and multi-faceted journey of becoming a scholar. Doctoral programmes differ between countries, institutions and disciplines in terms of their structure, development process and taught element; nevertheless, anxiety, uncertainty, loneliness and social isolation may often occur. Isolation and loneliness are likely to have a major impact on the student's psychological health and his/her wellbeing. According to Ali and Kohun (2006; 2007), students' isolation occurs at different stages of the doctoral program and contributes to attrition (drop-out) among doctoral students. This paper argues that relatively limited research has considered in combination the factors that contribute to these feelings of isolation and how students and institutions try to overcome them, if indeed they do. In response to this gap in knowledge, this paper examines the factors that influence isolation; but, more importantly, it considers the various coping mechanisms that may be adopted by doctoral students, as well as what institutions could do to tackle this issue.

Ali and Kohun (2006; 2007; 2009) offer useful indicative insights into loneliness among doctoral students; however, much of their work is theoretical, based principally on a review of related literature, or it is developed from institutional metrics and survey data from a relatively small sample. The themes of loneliness and friendship networks are often examined from the international student perspective with a specific focus on master's students' experiences. It can be seen that this topic has occupied researchers for a long period of time. For example, Owie's (1982) study of international students in the US found a high degree of isolation, while Sam and Eide's (1991) work showed that loneliness, tiredness, sadness and worrying were observed by nearly 1 in 4 students. Similar findings were reported by others: 
for example, Okorocha's (1996) study revealed loneliness to be endemic among international students, while Yang and Clum (1995) painted a portrait of depressed, anxious and lonely students. Researchers also tried to understand what caused such feelings and how these could be mitigated. Mori's (2000) study found high levels of stress in Asian students triggered by interpersonal problems; Bradley's (2000) survey of the needs of international students indicated a high degree of mental health problems, caused by isolation, and depression; and in a recent study, Brown (2009) highlighted the impact of loneliness on both well-being and friendship networks. It can be seen that while a substantial body of literature exists exploring international students' experiences of loneliness and friendships' networks, previous research has not focused on doctoral students.

The paper begins with a review of the literature drawn from a number of disciplines and research areas linking educational, management as well as cultural studies. It explores themes related to departmental experiences and international students' experiences. The subsequent section discusses the netnographic methodology adopted for the current study. The findings are presented in two parts: the first part looks at how doctoral students express their feelings of loneliness and isolation and in what stages of their doctoral journey they occur. The second part of the findings discusses the solutions provided by their peers. The paper ends with a discussion of emerging themes, suggestions on practices that could be implemented by institutions to decrease the experiences of isolation and loneliness among doctoral students, and it points avenues for further research. 


\section{Literature Review}

Berg et al. (1981) define loneliness as a feeling of the realisation of a lack of meaningful contacts with others and a lack or loss of companionship. Hortulanus et al. (2006) in their book on social isolation point out that a lack of meaningful relationships, which is increasing in the modern world, has a negative effect on the functioning and well-being of individuals. This should be of concern to institutions keen on improving their doctoral completion rates, as feelings of loneliness have been shown to affect academic performance as well as life satisfaction (cf., Ali and Kohun 2009; Lovitts 2001). Among the factors affecting the relationships and networks of doctoral students, existing research identifies: the role of an academic discipline, the role of peers, and student demographic, such as nationality.

Doctoral student experiences in different departments have been a focus of past research. It was suggested that in the social sciences, humanities and arts departments, doctoral students seem to be more prone to isolation, whereas in the natural sciences and technology, doctoral research takes place within formal research teams where social groups are already established, hence social isolation is less of a problem (Deem and Brehony 2000; Delamont et al. 1997). Chiang's study (2003) examines this further by comparing perceptions of doctoral students in Chemistry and Education across a number of UK departments. Students in the social sciences work on different projects from their supervisors, and research students are regarded as learners rather than full members of the research group. Conversely, in science, there is frequent contact among all researchers, both doctoral students and professors: "due to the emphasis of teamwork, close interaction and a sense of collegiality, the overall atmosphere in the department appears to be casual, friendly and lively" (Chiang 2003, 20). This may explain why completion rates in science departments are reported to be much higher (Park 2005; 
Seagram et al. 1998; Wright and Cochrane 2000) and why doctoral studies in these fields are frequently shorter (Jiranek 2010).

While it may be possible to argue that science departments are less prone to the problem of isolation, in a recent paper Walsh (2010) reported that international students in engineering and sciences also experienced isolation: they encountered a lack of integration with the student body as well as cultural and communication difficulties. This reinforces the need to consider the potential influence of other factors, including nationality and the role of social networks in general on students' experiences of isolation.

The role of peers in doctoral students' experience has received some attention (Gardner 2007; Hadjioannou et al. 2007; Walsh 2010). Gardner (2007) revealed that students both in history and chemistry highlighted the importance of support from their peers. The newer students look to more advanced ones as mentors. Recruitment weekends in the department, the induction week and graduate student organisations facilitated the development of new ties. In a different study, Hadjioannou et al. (2007) demonstrated that student-led groups improve the academic skills of doctoral students as well as playing an important emotional supporting role. The reliance on former and existing students for instrumental and emotional support has also been observed in the postgraduate (Masters) student population (see Brown 2009). Finally, as mentioned previously, Walsh (2010) questioned how overseas doctoral students in science departments felt about the levels of integration with home and other students. A combination of cultural issues and language difficulties acted as a hindrance to socialising with domestic students. This is not a surprising finding: limited social interaction with domestic students is a common theme in educational research (Brown 2009). Despite claims for the benefits of internationalisation at policy level, most studies of the international campus 
have observed a lack of integration between students groups, lending weight to Ward's (2001) claim that the benefits of the international campus are hypothesised and empirically untested. As de Vita $(2005,75)$ states, "the ideal of transforming a culturally diverse student population into a valued resource for activating processes of international connectivity, social cohesion and intercultural learning is still very much that, an ideal." To international student dissatisfaction, a low incidence of bonds between international and local students has been long and widely documented (i.e. Bochner et al. 1977; Brown, 2009; de Vita 2005). Thus international students are denied the optimal route to improving language and host cultural knowledge (Brown 2008). Clearly, the available studies are too few to understand this aspect sufficiently and address this in the design of doctoral programmes.

A large body of literature on doctoral candidates is dedicated to the general experiences of international students (i.e. Borg et al. 2009; Ingleton and Cadman 2002; Robinson 2008). Unsurprisingly, international students experience loneliness, especially at the beginning of the doctoral process. A lack of integration of international students has been one major theme. For example, it has been demonstrated that foreign students, both undergraduate and postgraduate, often socialise within their own ethnic groups (Brown 2009). Indeed, the most common friendship group noted in studies of interaction patterns is the monocultural bond: a ghetto pattern is usually observed by researchers (Bochner et al. 1977; Brown 2009) and the willingness to leave the confines of the monoethnic group is a rare phenomenon (Gudykunst 1998). It is acknowledged that friendships with compatriots serve an important function in diminishing loneliness and stress but they are also accredited with decreased intercultural interaction and reduced language progress (Bochner et al. 1977; Wiseman 1997; Yang and Clum 1995). 
Often, foreign students' expectations, needs and behaviours differ and their culture can have a great impact on their educational experience. For example, Hofstede's (2001) cultural dimensions may explain why Asian students, who originate from collectivist societies, may experience difficulty at the beginning of their educational experience in Western countries. Some evidence suggests that Asian doctoral students in the UK were not expecting to work in isolation or to receive limited guidance from their supervisors (Borg et al. 2009). Evans and Stevenson (2010) point out that it is difficult for students originating from cultures where they are expected to be passive recipients of knowledge to undertake doctoral studies in countries steeped in the western pedagogical tradition where the student is a self-directed learner and critical thinker. According to Dickinson (1993), for many international students, the ideal supervisor is one who offers regular tutorials and considerable structure. Students and lecturers often have different expectations of the teacher-pupil relationship, the roles of student and lecturer and the locus of responsibility for learning (Brown 2008): in the West, it is assumed that supervisors should develop students as independent learners (Ballard and Clanchy 1997). According to Channell (1990), if the expectation of the western academic system is that students work independently and creatively, then they will need more supervision at first as they do not know that this is the learning style: students often feel they need to be eased into self-responsibility. For staff, however, they simply may not have the time to dedicate to a student unused to Western academic culture, and they may expect the student to be independent straight away (Brown 2008). Meanwhile, whilst desiring more contact than the supervisor is willing to give, owing to their former mode of education in a hierarchical structure, many international students find it very difficult to approach their supervisor (Channell 1990). Consequently, if students do not express the need for help, supervisors may assume that they do not need it (Cortazzi and Jin 1997). The Committee of Vice Chancellors and Principals (CVCP) code of recommended practice on postgraduate 
teaching states that overseas students require sensitive treatment. However, as staff are often too busy to deal with the particular needs of international students, there is clearly a conflict between an institution's desired income and the level of resources available to deliver the service expected by students. Academic cultural dissonance leads to a mismatch in expectations which may increase the feeling of loneliness. It is interesting to note that studies in this area focus mostly on the initial stage of the doctoral journey, and therefore more research is needed to analyse international students' experiences at the final stages, close to examination.

Although social isolation and loneliness have received some research attention in the context of international students at both undergraduate and postgraduate level, there is still a dearth of research in understanding the experiences of doctoral students. This paper looks at the context in which doctoral students encounter loneliness and social isolation, the tactics they use to overcome them and the solutions their peers offer. It looks not only at international but also domestic students who may be in close proximity to their family and existing networks, but still encounter loneliness during the doctoral process. This study contributes to the literature on the doctoral student experience by discussing students' perceptions of loneliness and isolation as well as departmental and informal support.

\section{Methodology}

This study used netnography to collect primary data. This term, made up of internet and ethnography, was coined by Robert Kozinets in the 90s and was initially used for conducting consumer research and marketing on the internet (Kozinets 2010). Netnography and related forms of investigative internet-based research (Lugosi et al. 2012) are an 'economical, 
effective and unobtrusive means of studying 'naturally occurring' online communication and behaviour' (Bengry-Howell et al. 2011, 3). Due to high growth in internet fora and easy access to rich data, this form of data collection is widely accepted and used in many fields, including business, marketing, economics, management, information systems, cultural studies and sociology (see Bengry-Howell et al. 2011 for a discussion of netnography's use across disciplines and O'Reilly et al. 2007 for its application in education).

Kozinets (2010) provides detailed guidance on how to conduct netnographic research. He outlines six criteria for selecting sites for study, arguing that they should be: 1) relevant to the research focus and questions, 2) active, with recent and regular communications, 3) interactive, having flows of communication between participants, 4) substantial, in terms of numbers of users, 5) heterogeneous, involving different participants, and 6) data-rich (2010, 89). Moreover, he suggests the following stages in conducting research: entry into the 'community', data collection, analysis and interpretation as well as member feedback. Although these steps are followed in some studies, for example, in an educational setting (O'Reilly et al. 2007), these procedures have been modified by others who have developed arguments for conducting studies without informing users (see Langer and Beckman 2005; Beaven and Laws 2007; Janta et al. 2012). It has been argued that the public nature of online fora negates the need to seek informed consent when using them as a source of data.

For the purpose of this research a data rich and active site for doctoral students around the world was selected. In order to provide some level of anonymity for contributors, we have decided not to publish the site's name; nor do we publish the usernames of the individual posters; however, the public nature of the fora means it is not possible to completely anonymise the data as in other forms of qualitative research. The forum's aim, as specified on 
the website, is to support current, future and previous postgraduate students to exchange ideas and get advice. The traffic on this site was found to be extremely active. One thread: 'The one goal thread', was launched in April 2010, and 14 months later, reached 47,544 views and 2914 replies consisting of 196 pages of text (approximately 180,000 words). Specific threads were found using the following keywords: 'loneliness' and 'lonely'. Approximately 35 existing threads (in total 122 pages), launched between 2007 and 2011, such as 'dealing with loneliness', 'feeling frustrated and alone' and 'lonely' were downloaded, printed and analysed.

The data were subjected to the thematic analysis technique described by Braun and Clarke (2006). This involved initial familiarisation with the data through reading and re-reading specific postings. The next step was developing codes, which were identified manually: recurrent words and phrases were highlighted until key categories were formed. The metathemes to emerge were: sources of loneliness, social interactions, interactions outside academia, professional development and online forum. The quotes are used with the original spelling (the use of apostrophes, capital letters etc.) and punctuation. On a few occasions, some quotes have been edited because of their length.

Although it is believed that the data set from this particular forum is data-rich, it needs to be acknowledged that a limitation of this study is that in a few cases it was difficult to identify the specific department of the doctoral student and the mode of study i.e. whether the participant was a full- or part-time student. It is also important to acknowledge the broader limitations of using netnographic or internet-based investigative approaches in examining a specific forum, which have been discussed elsewhere (Lugosi et al. 2012). These approaches exclude those who do not use this forum and only focus on active contributors rather than passive observers. Nevertheless, the findings yielded a number of themes that contribute to 
existing knowledge on the experiences of doctoral students and highlight emerging themes that may be explored in future research.

\section{Findings}

\section{Feeling lonely and isolated}

A number of threads contained words such as 'loneliness' or 'lonely' in their titles: 'Loneliness of a PhD student', 'Loneliness of the long-distance researcher', 'Lonely', 'PhD loneliness: Common theme?' Clearly, doctoral students were expressing their feelings to and looking for support from others experiencing similar issues. Loneliness itself was expressed in a number of ways, varying from general feelings of boredom and loneliness to more alarming signs of depression. While most of the issues relating to anxiety and loneliness occur in the first few months of the doctoral process (cf., Ingleton and Cadman 2002), different experiences exist. For example, a foreign candidate studying for a doctorate in a Nordic country expressed her problem in the following way:

(...)I get good funding and my advisor is a great guy. I would say professionally, everything is just great. However, after 1 year, except for some not so deep attachments with some of my peers, I have been unable to make any friend. The days just go by completely alone, and as I am an international student I don't have family or similar here. I am 100\% alone day and night, all the time. I am alone in my office all day, get up, go to my house to be alone. When the weekend comes, I stay alone at my home, go to do shopping alone, and so on. (thread: Loneliness as a PhD student, 22.10.2009) 
It has been claimed that supervisors can make or break a doctoral student's experience (Lee 2008, 267). The findings in this research however suggest that doctoral students may make good progress, have satisfactory relationships with their supervisors, but a lack of social interactions made them unhappy. Indeed, such feelings frequently emerge among international students. A study conducted among foreign postgraduate students showed that life in a new country can be extremely difficult at the beginning (see Brown and Holloway 2008). The first stage of the sojourn is marked by experience of the symptoms associated with culture shock, including homesickness, sleeplessness, tearfulness, loneliness, fear, disorientation, and depression. In addition, being separated from others makes settling in a foreign country even harder. Interestingly, similar concerns about isolation are expressed by a domestic student who has an office by himself and misses social interaction:

I'm sorry if this appears like another negative thread, because I'm very lucky; I have great supervisors and am generally getting on OK with my PhD (after a rough few months over xmas!), so I know other people have far worse issues... Basically, I'm a bit lonely! There are roughly 12 students here, all sharing offices but I'm on my own (my office mate has quit their PhD so just in occasionally writing up for MPhil, no room for me in another office). I'm not socially inept--I do go and chat but obviously if you're sharing an office it's different. I came in this morning feeling really happy and chatty, I even printed something I didn't need to just so I could go into someone else's office: shame: but everyone was busy. (thread: Feeling a bit lonely, 16.04.2007)

Clearly, it is crucial that host institutions provide appropriate social and learning spaces for doctoral students. Those in the final stages of writing their thesis may appreciate a quiet room; 
however, in the early stages, working in such a space may contribute to feelings of isolation and a lack of belonging to a group. A different example is brought up by a student who is the only doctoral candidate in a department:

I have my own office situated within an academic department. One of my supervisors wants me to stick to my departmental office like glue (which can make research trips such as to the British library difficult) whilst the other supervisors (located in my other department) are more relaxed about my whereabouts. I'm the only student here and Im surrounded by researchers, academics, secretaries etc. I also live in corridors on the postgrad accommodation block and there are very few phds around. I therefore tend to socialise with MSc students. The only first year PhD students i've met are international students (who struggle with english, which makes socialising difficult), keep to themselves and dont want to socialise or live miles away from campus. There are days when it does bother me, such as I dont feel like im a PhD student at all, and feel like im the only phd student in existence! (thread: PhD loneliness. A common theme? 20.03.2007).

It seems that although the student tried to develop relationships with their peers, physical isolation was a barrier. Clearly, physical proximity with peers sharing a similar experience is important, especially during the initial stage of the program. This is the case when there is only one doctoral student in the department who is given a separate office. Another comment by a student from a small university claimed they were not given a room at all and were using the library instead. Previous research has shown that support from both the faculty and peers are needed for degree success (Gardner 2007), and the data suggests that the physical and spatial dimensions of the doctoral experience may be undermining. 
As discussed in the literature review, it has been argued that students from science departments are more immune to isolation because they often work in larger groups and are part of a bigger project (Deem and Brehony, 2000; Delamont et al. 1997; Chiang 2003). While there was a discussion between arts doctoral students (thread: 'Coping with loneliness') who shared their thoughts on researching arts and loneliness related to the act of working on their own, there were also comments from science students. For example, a British student in a Chemistry department commented:

Hi, I have just started my PhD in Manchester (chemistry). I am from Scotland and don't have any friends here. I have been out with some lab colleques but they are older and have families. I am feeling a bit lonely with starting the PhD. Any suggestions what to do? (thread: Lonely, 21.09.2005).

In a different thread ('Coping with loneliness'), a science student confessed that: 'Giving up all interaction with the outside world is a BIG sacrifice'. Although science students may work together and have a sense of collegiality (Chiang 2003), if they are in different stages of their life, it may be difficult for them to interact socially outside work. Moreover, a recent study by Walsh (2010) demonstrated that overseas science students felt isolated because they lacked integration with domestic students. These comments illustrate that every case should be analysed individually, and generalisations should be avoided.

It was argued previously that social isolation is a major factor contributing to high attrition rates (Ali and Kohun 2006). Yet, despite this recognition, isolation has yet to be addressed fully in the design of some doctoral programs. It is possible that doctoral students-to-be have 
expectations of becoming part of a sociable, active, young research community, and when their expectations are not met, they feel extremely disappointed, as the following comment illustrates: 'I guess when I started, I thought new chapter, big adventure, new people. In reality it's me in my living room at my computer (...)' (thread: Loneliness of a long-distance researcher, 6.03.2011). This comment echoes Walsh's (2010) observation that the desire for integration with other students sometimes resulted in feelings of having been misled by materials seen during the recruitment process. Clearly, in the light of reduced funding for HE in many parts of the world and a growing desire to increase the number of foreign students, this is a theme that needs further investigation.

From these commentaries it can be seen that both groups, domestic and international doctoral students, encounter similar disappointments and experience similar feelings of isolation and loneliness, even when they are close to home: I feel lonely doing my PhD and I live in my home town! (thread: Loneliness as a PhD student, 22.10.2009).

The process of becoming a scholar may be a long and lonely journey of transformation that can be seen as 'a rite of passage' (Barton 2007) - a transitional process when a person moves from one social status to another (van Gannep 1960). Such a rite of passage involves a liminal stage: when people lose one fixed status, but have yet to achieve another fixed status (Turner 1969). Liminality is fraught with ambiguity, resulting in a sense of isolation. This notion of liminality can be used to interpret some commentaries. For example, from being a sociable person, a student from a prestigious US university started contemplating quitting after less than a year. From being: 'full of life, extremely sociable, and very ambitious' she became depressed and anti-social: 
Sometimes I am so depressed that it's very hard to even get through the day. I feel that the loneliness and lack of any meaningful social outlet is tearing me apart inside. At first, I tried to network with everybody and even organized social events. But eventually I got tired because people started giving me a suspicious attitude that basically said: "If you are so social, what the hell did you come here for?" A few even asked me why I didn't go for a business degree instead, suggesting that I didn't belong here, just because I am a little bit more normal than they are. And they started avoiding me. I'm already depressed and anti-social. I don't know what kind of a person I will turn into if I persist in this emotionally dysfunctional environment for 3 or 4 more years. Part of me is telling myself that as a self-responsible person I can't let this go on. (thread: Want to Quit PhD... Please help, 24.04.2009).

This excerpt points to the way feelings of isolation may be intensified by others. Indeed, many comments reflected the difficulty of finding people to relate to. Cultural differences may explain this to a certain degree, but individual characteristics and values also interact.

An overview of different threads posted on the forum suggests that loneliness may be a part of many people's doctoral experience. Most of the users pointed out that their case was not individual and that they were aware that others felt similarly. Some comments were related to the differences between MSc programs and doctoral programs or a lack of support from administration; rarely, were supervisors blamed. As discussed previously, while some students felt they were progressing, as acknowledged by their supervisors, the lack of social interaction and being part of a social group made them feel lonely and even depressed. 


\section{Strategies for coping with loneliness and isolation}

Most of the threads were launched on the doctoral forum in order to receive some emotional and practical support from their peers. Although it was clear that many of them tried to use different tactics, such as meeting other doctoral candidates, going out or joining a gym, for many these strategies did not work, thus they were seeking advice on other possible solutions. Replies posted by others could be divided as follows: social interactions (face to face and online), professional development and escape from the doctorate.

\section{Interacting with peers}

Most of the comments pointed to the importance of others and becoming proactive in finding friends. Some suggested organising events with other students such as lunches, nights out, networking, discussing research and setting up doctoral groups. Examples include: 'You cant do this alone! The student group will help you get through it, and you might even find yourself pushing and motivating others in the process'. (thread: Want to quit PhD. Please help, 15.05.2009) and 'Maybe you could suggest a meal out with a few of the people you've met. You could perhaps make it a departmental thing, i.e. all the first year PhDs and it'll feel less personal and you can meet more people (thread: Feeling frustrated and alone, 17.05.2010). Indeed, Hadjionnau et al. (2007) described how student-led doctoral groups created a dynamic supportive community and provided its members with essential emotional sustenance.

\section{The doctoral forum}

On a number of occasions it was acknowledged that the forum itself was supportive and was a means of coping: 'This website is therefore a welcome relief to read similar experiences to my own!' (thread: PhD loneliness: a common theme, 20.03.2007) Furthermore, a positive 
comment from a disabled student was made about the essential role of the forum during his rather isolated doctoral journey:

I completed my part-time PhD basically from home. I'm severely disabled, and couldn't go into the uni very much at all. I felt incredibly isolated, but focused on what I needed to do, and used this forum for added support. (...) (thread: Loneliness of the long-distance researcher, 16.03.2011)

For this particular doctoral student, the forum acted as the hospitable social space he needed. Being excluded from face to face contact with other peers, he was able to actively participate on-line in discussion about doctoral student life. A study conducted by Naughton et al. (2010) suggests that such portals were crucial: the ISchool $\mathrm{PhD}$ experience created at Drexel, US, connected doctoral students, and their forum was one of the essential features of the portal. Similarly, for professional doctorates, such a portal can play an important role for students (Beutel et al. 2010) and supervisors (Crossouard 2008). In the case of disabled students, the online forum arguably plays a hugely significant role. This is an issue that needs more attention in research.

\section{Professional development}

Some suggestions pointed to the professional and productive use of time to enhance doctoral candidates' future career such as finding teaching opportunities on campus: 'Preparing for class can be time consuming, which will lead to less time alone and at home thinking about why you should not be there (thread: Want to Quit PhD...Please Help', 24.08.2009). Looking for opportunities to work as a professor's assistant was another suggestion: 'This might even lead to conference presentations, and even possibly a publication. At the very least, it will get 
you some experience conducting research, collecting and/or analysing data' (thread: Want to Quit PhD...Please Help', 24.08.2009). Stoilescu and McDouglas (2010) suggest that preparing publications and acting as a reviewer is also an important and a productive use of time.

Accumulating teaching experience, attending conferences and developing professional networks will surely contribute to students' success in academia. To this end, supervisors play a major role in assuring that their student is actively engaged in both professional development and networking. Becker et al. (2010) argue that providing students with contacts with research communities was one of the major expectations of doctoral students from their supervisors. Furthermore, attending conferences and networking with other doctoral students as well as other academics should help decrease students' isolation.

\section{Escaping the academic world}

Although it was highlighted by almost all the participants that it is crucial to have support from others, some comments suggested meeting people from outside academia, in order 'to keep sanity'. Attending language classes was also highlighted a number of times as a means of finding friends. For international students, learning the local language could also assist in adaptation to the new society (Hofstede 2001; Ward et al. 2001).

A PhD drop-out suggested dance classes:

In the last six months I was doing my PhD pretty much the only thing that helped me hang on to my sanity was going to a local dance class. Nobody there gave a hoot about experiments, papers, supervisors or whatever - it was pure escapism. Plus exercise is good for your mental state. So get out there and meet other people, and 
then your PhD won't eat up your entire life. (thread: Want to Quit my PhD... Please help,

Another option suggested by contributors for meeting like-minded people was to become involved in one of the increasing number of non-commercial hospitality organisations such as couch-surfing: 'These are primarily for backpackers to look for a place to crash when travelling, but I suspect many members are also up for meeting up for drinks and hanging out with people who've moved to their city/country'. (thread: Loneliness as a PhD student, 22.10.2009). 'Couch surfing', with three million members in more than 200 countries, is a volunteer-based worldwide network connecting travellers with members of local communities, who offer free accommodation and/or advice (Couchsurfing 2011). Hence, it is a way of socialising acting either as a guest or a host, and provides opportunities to meet both local and foreign people (Germann Molz 2012).

Overall, suggestions made by forum users point to attempts to achieve the right balance between the doctoral process and private life. Recently, the idea that work should be 'balanced' with activities outside of work has become important for many organisations, policy makers and society (Jones 2003) as it contributes to individual well-being (Halpern 2005). Different solutions have been listed by online users to achieve the right balance in life such as: taking care of animals or plants, playing sports or joining clubs and societies. All of these activities are supposed to separate student and personal life.

\section{Conclusion}

The findings from this study suggest that both domestic and international students from a 
range of disciplines experience social isolation, suffer a lack of emotional support and may struggle to engage in meaningful relationships with their peers. The study suggests that social isolation is a problem that needs to be considered at the broader institutional and specific departmental level. The contractual nature of the relationship between institution and student should thus include structures and cultures of support for students that directly address social isolation. Any promises regarding support made to prospective students in promotional materials and recruitment activities should be honoured by receiving institutions once students arrive, not only to enhance student satisfaction and retention but also to improve recruitment through positive word of mouth. In the case of international students, in particular, ethical recruitment means that support is offered on an ongoing basis once they have been successfully recruited. Such support strategies to reduce social isolation require investment on the part of HEI to demonstrate their commitment to alleviating the stressful aspects of the doctoral experience. This may require strategic institutional investment in the design of working spaces alongside the development of the organisational and research culture. This is also likely to involve appropriate training for supervisors to be aware of the signs of social isolation and to be able to point students to appropriate sources of support. Support may come from the institution, for example, in the form of counselling, or, as we argue below, in the facilitation of social interaction. However, it is likely to come from colleagues, peers and supervisors, who are a) socially closer to the student, and b) in a better position to empathise with the sense of isolation associated with the doctoral experience.

This study has argued that many of the issues surrounding loneliness relate to particular departmental and disciplinary cultures. The data suggest that student-supervisor relationships were often satisfactory, but students did not necessarily expect emotional support from academic advisors. This raises questions concerning the supervisor's role. Lee (2008) 
considered multiple dimensions of doctoral supervision and found that developing a 'quality relationship', which included caring for the student, is one type of relationship open to supervisors. However, there is evidence showing that supervisors may become too emotionally involved which may have negative consequences for the relationship (Hockey 1995). This suggests that further research is needed to consider the appropriateness and extent of pastoral care provided by supervisors. In addition, it would be beneficial to examine further what type of emotional and pastoral care doctoral students from different nationalities and cultural backgrounds expect from their supervisors.

A range of other factors may influence doctoral students' social isolation. One theme that emerged from this study is the importance of space in shaping student experiences. It can be assumed that doctoral students at most universities are provided with a study area where they can work. However, it is clear that a learning space should not be thought of as a hygiene factor that only causes dissatisfaction if it is absent or not addressed adequately. Rather it is important for institutions to appreciate space as a critical factor that can not only substantially enhance the doctoral experience but also significantly damage it. This involves recognising the different uses of space at different stages of the doctoral experience: for example, discrete work spaces may be essential when writing up a thesis, but may reinforce isolation and social exclusion during earlier stages. Empirical research into the multiple functions of space may enable institutions to anticipate and actively respond to the shifting needs of doctoral candidates.

A second factor is the social interaction facilitated by colleagues, the department and the institution. There are a number of activities that could be organised and managed by departments and institutions. Interaction opportunities may include welcome events for new 
entrants, convivial celebrations of the achievement of key milestones, lunchtime seminars combining food and drink with academic debate, alongside other hospitable gatherings. While some research-intensive universities may have the culture and resources to support such initiatives, this may be more challenging for institutions with a less developed research environment. It is also important to be mindful that events have to be appropriate to both domestic and foreign students. For example, a quiz is a popular form of socialising in some cultures; however, in order for all doctoral students to participate, they need to limit local cultural references which may otherwise reinforce a student's sense of exclusion. Another consideration may be the choice of venue. While a drinking venue may be a common social space in certain countries, it may not be appropriate for students coming from other cultural backgrounds, for example Muslim students. It would be helpful to examine whether such networking events reinforce or negate feelings of isolation among different student groups.

Networking is another theme that emerged from this study. Attending seminars, workshops and conferences serves professional and social purposes. Academic networking can help to develop professional contacts, facilitating socialisation into academic networks whilst potentially addressing the challenges of isolation. However, it would be useful to consider, through empirical research whether such events serve as forms of detachment from the doctoral experience or forms of reattachment, reinforcing the broader gains of engaging in doctoral studies and academic careers. It may also be useful to explore whether negative experiences of academic networking may actually reinforce a sense of social isolation.

A final theme that emerged from this research is the role of online fora. It can be seen that the forum examined in this study was significant for doctoral students from around the world. Online environments have already been used in professional doctorates to support doctoral 
studies (see Crossouard 2008). With the recent expansion of virtual learning across universities, online fora could easily be utilised by institutions or departments to enhance the student experience. While the forum chosen for this study acts as an effective, informative and emotionally supportive platform, such fora could also be established at an institutional level to support students. This would complement existing initiatives designed to support doctoral students. Moreover, examining doctoral students' interactions, through netnographic and other investigative internet-based studies, can highlight specific concerns whilst also helping to identify potential solutions that address the challenges of isolation and loneliness. 


\section{References}

Ali, A., and F. Kohun. 2006. Dealing with isolation feelings in IS doctoral programs. International Journal of Doctoral Studies 1: 21-33.

Ali, A., and F. Kohun. 2007. Dealing with social isolation to minimize doctoral attrition - A four stage framework. International Journal of Doctoral Studies 2: 33-49.

Ali, A., and F. Kohun. 2009. Cultural influence on Social isolation in doctoral programs and doctoral attrition - A case study. Available online at: Information Systems Education Journal 7, no. 64: http://isedj.org/7/64/ (accessed 1 March 2012).

Ballard, B., and J. Clanchy. 1997. Teaching international students. Deakin: IDP.

Barton, T. D. 2007. Student nurse practitioners - a rite of passage? The universality of Van Gennep's model of social transition. Nurse Education in Practice 7: 338-347.

Beaven, Z., and C. Laws. 2007. 'Never Let Me Down Again': Loyal customer attitudes towards ticket distribution channels for live music events: A netnographic exploration of the US leg of the Depeche Mode 2005-2006 World Tour. Managing Leisure 12: 120-142.

Becker, P., M. Bengtsson, D. Nilsson, and B. Nordquist Becker. 2010. Approaches to doctoral supervision in relation to student expectations. Available online at: Lund University http://www.brand.lth.se/fileadmin/brandteknik/utbild/Pedagogik/resurser/Report_final_versi on_.pdf (accessed 1 March 2012). 
Bengry-Howell, A., R. Wiles, R. Nind, and G. Crow. 2011. A review of the academic impact of three methodological innovations: netnography, child-Led research and creative research methods. Available online at: ESRC National Centre for Research Methods, NCRM Working $\begin{array}{lll}\text { Paper } & \text { Series, } & 01 / 2011\end{array}$ http://eprints.ncrm.ac.uk/1844/1/Review_of_methodological_innovations.pdf (accessed 1 March 2012).

Berg, S., D. Mellstrom, G. Persson, and A. Svanborg. 1981. Loneliness in the Swedish Age. Journal of Gerontology 36(3): 342-49.

Beutel, D., L. Gray, S.Y. Beames, V. Klenowski, L. Ehrich, and C. Kapitzke. 2010. An exploratory study of online social networking within a Doctorate of Education program. International Journal of Learning 17(3): 67-79.

Bochner, S., B. McLeod, and A. Lin. 1977. Friendship patterns of overseas students. International Journal of Psychology 12(4): 277-294.

Borg, M., R. Maunder, X. Jiang, E. Walsh, H. Fry, and R. Di Napoli. 2009. International students and the academic acculturation process: the role of relationships in the doctoral process, In Internationalisation and the student voice, ed. E. Jones, 181-207. London: Routledge.

Bradley, G. 2000. Responding effectively to the mental health needs of international students. Higher Education 39, 417-433. 
Braun, V., and V. Clarke. 2006. Using thematic analysis in psychology. Qualitative research in Psychology 3: 77-101.

Brown, L. 2008. Language and anxiety: An ethnographic study of international postgraduate students. Evaluation and Research in Education 2(3): 75-95.

Brown, L. 2009. An ethnographic study of the friendship patterns of international students in England: An attempt to recreate home through conational interaction. International Journal of Educational Research 48(3): 184-193.

Brown, L., and I. Holloway. 2008. The adjustment journey of international postgraduate students at an English university: An ethnographic study. Journal of Research in International Education 7(2): 232-249.

Channell, J. 1990. The student-tutor relationship, In The learning experiences of overseas students, ed. M. Kinnell, 63-81. Buckingham: OUP/SRHE.

Chiang, K. H. 2003. Learning experiences of doctoral students in UK universities. International Journal of Sociology and Social Policy 23(1/2): 4-32.

Cortazzi, M., and L. 1997. Learning across cultures, In Overseas students in HE: issues in teaching and learning, ed. D. McNamara, and R. Harris, 76-90. London: Routledge. 
Couchsurfing 2011. Available online at: http:/www.couchsurfing.com (accessed 1 March 2012).

Crossouard B. 2008. Developing alternative models of doctoral supervision with online formative assessment Studies in Continuing Education 30(1): 51-67.

de Vita, G. 2005. Fostering intercultural learning through multicultural group work, In Teaching international students: Improving learning for all, ed. J. Carroll, and J. Ryan, 75-83. London: Routledge.

Deem, R., and K. Brehony. 2000. Doctoral students' access to research culture - are some more equal than others? Studies in Higher Education 25(2): 149-165.

Delamont, S., O. Parry, and P. Atkinson. 1997. Critical mass and pedagogic continuity: Studies in academic habitus. British Journal of Sociology of Education 18(4): 533-549.

Dickinson, J. 1993. The management of higher degrees undertaken by overseas students. Journal of International Education 4(1): 41-44.

Evans, C., and K. Stevenson. 2010. The learning experiences of international doctoral students with particular reference to nursing students: A literature review. International Journal of Nursing Studies 47: 239-250.

Gardner, S. 2007. "I heard it through the grapevine": Doctoral student socialisation in chemistry and history. Higher Education 54(5): 723-740. 
Germann Molz, J. 2012. CouchSurfing and network hospitality: 'It's not just about the furniture'. Hospitality and Society 1(3): 215-225.

Gudykunst, W. 1998. Bridging differences: Effective intergroup communication. London: Sage.

Hadjioannou, X., N. Shelton, F. Rankie, and D. Danling. 2007. The road to a doctoral degree: Co-travellers through a perilous passage. College Student Journal 41(1): 160-177.

Hockey J. 1995. Getting too close: A problem and possible solution in social science PhD supervision. British Journal of Guidance and Counselling 23(2): 199-210.

Hofstede, G. 2001. Culture's consequences: Comparing values, behaviors, institutions and organizations across nations. London: Sage.

Hortulanus, R. P., A. Machielse, and L. Meeuwesen. 2006. Social isolation in modern society. London: Routledge.

Ingleton, C., and K. Cadman. 2002. Silent issues for international postgraduate research students: Emotion and agency in academic success Australian Educational Researcher 29(1), 93-113.

Janta, H., P. Lugosi, L. Brown, and A. Ladkin. 2012. Migrant networks, language learning and tourism employment. Tourism Management 33(2): 431-439. 
Jiranek, V. 2010. Potential predictors of timely completion among dissertation research students at an Australian faculty of sciences International Journal of Doctoral Studies 5: 1-14.

Jones, A. 2003. About time for change. The Work Foundation, in association with Employers for Work-life Balance. Available online http://workfoundation.net/assets/docs/publications/177_About\%20time\%20for\%20change.pdf (accessed 1 March 2012).

Kozinets, R. V. 2010. Netnography: Doing ethnographic research online. London: Sage.

Langer, R., and S. Beckman. 2005. Sensitive research topics: Netnography revisited. Qualitative Market Research: An International Journal 8(2): 189-203.

Lee, A. 2008. How are doctoral students supervised? Concepts of doctoral research supervision. Studies in Higher Education 33(3): 267-281.

Lovitts, B. E. 2001. Leaving the ivory tower: The causes and consequences of departure from doctoral study. Lanham, MD: Rowman and Littlefield).

Lugosi, P., H. Janta, and P. Watson. 2012. Investigative management and consumer research on the internet. International Journal of Contemporary Hospitality Management 24(6): 838854. 
Mori, S. 2000. Addressing the mental health concerns of international students. Journal of Counselling and Development 78(2): 137-144.

Naughton, R. A, C. E. Hall, H. Zhao, and X. Lin. 2010. Developing an Online iSchool Doctoral Student Community. Available online at: https://www.ideals.illinois.edu/handle/2142/15058 (accessed 1 March 2012).

Okorocha, E. 1996. The international student experience. Journal of Graduate Education 2(3): $80-84$.

O'Reilly, N., R. Rahinel, K. Foster, and M. Peterson. 2007. Connecting the megaclasses: The netnographic advantage. Journal of Marketing Education 29(1): 69-84.

Owie, I. 1982. Social alienation among foreign students. College Student Journal 16(2): 163165.

Park, Ch. 2005. War of attrition: Patterns of non-completion amongst postgraduate research students. Higher Education Review 38(1): 48-53.

Robinson, S. 2008. To be or not to be? Doctoral science students' experiences, 2nd International Conference on Preparing for Academic Practice: Disciplinary Perspectives. University of Oxford, 8-9 April. Available online at: http://www.learning.ox.ac.uk/files/file/Sean\%20Robinson.ppt\#1 (accessed 1 March 2012).

Sam, D., and R. Eide. 1991. Survey of mental health of foreign students. Scandinavian 
Seagram, C. B., J. Gould, and S. Pyke. 1998. An investigation of gender and other variables on time to completion of doctoral degrees Research in Higher Education 39(3): 319-335.

Stoilescu, D., and D. McDougall. 2010. Starting to publish academic research as a doctoral student. International Journal of Doctoral Studies 5: 79-92.

Turner, V. 1969. The ritual process: Structure and anti-structure. Chicago: Aldine.

Walsh, E. 2010. A model of research group microclimate: Environmental and cultural factors affecting the experiences of overseas research students in the UK. Studies in Higher Education 35(5): 545-560.

Ward, C. 2001. The impact of international students on domestic students and host institutions, New Zealand Ministry of Education. Available online at: http://www.minedu.govt.nz/index.cfm?layout=index\&indexID=2107\&indexparentid=1000 (accessed 1 March 2012).

Ward, C., S. Bochner, and A. Furnham. 2001. The psychology of culture shock. Hove: Routledge.

Wisemann, H. 1997. Far away from home: The loneliness experience of overseas students. Journal of Social and Clinical Psychology 16(3): 277-298. 
Wright, T., and R. Cochrane. 2000. Factors influencing successful submission of PhD theses. Studies in Higher education 25(2): 181-195.

Van Gennep, A. 1960. The rites of passage. London: Routledge and Kegan Paul.

Yang, K., and G. Clum. 1995. Measures of life stress and social support specific to an Asian student population. Journal of Psychopathology and Behavioural Assessment 17(1): 51-67. 